\title{
Escape from stimuli correlated with transitions across lean and rich schedules of reinforcement
}

August F. Holtyn

West Virginia University

Follow this and additional works at: https://researchrepository.wvu.edu/etd

\section{Recommended Citation}

Holtyn, August F., "Escape from stimuli correlated with transitions across lean and rich schedules of reinforcement" (2010). Graduate Theses, Dissertations, and Problem Reports. 3000.

https://researchrepository.wvu.edu/etd/3000

This Thesis is protected by copyright and/or related rights. It has been brought to you by the The Research Repository @ WVU with permission from the rights-holder(s). You are free to use this Thesis in any way that is permitted by the copyright and related rights legislation that applies to your use. For other uses you must obtain permission from the rights-holder(s) directly, unless additional rights are indicated by a Creative Commons license in the record and/ or on the work itself. This Thesis has been accepted for inclusion in WVU Graduate Theses, Dissertations, and Problem Reports collection by an authorized administrator of The Research Repository @ WVU. For more information, please contact researchrepository@mail.wvu.edu. 
Escape from Stimuli Correlated with Transitions across Lean and Rich

Schedules of Reinforcement

August F. Holtyn

Thesis submitted to the Eberly College of Arts and Sciences at West Virginia University in partial fulfillment of the requirements for the degree of

Master of Science

in

Psychology

Michael Perone, Ph.D., Chair

Kennon A. Lattal, Ph.D.

Kevin T. Larkin, Ph.D.

Department of Psychology

Morgantown, West Virginia

2010

Keywords: aversive stimuli, fixed-ratio, post-reinforcement pause, stimulus termination, pigeons 


\section{ABSTRACT \\ Escape from Stimuli Correlated with Transitions across Lean and Rich Schedules of Reinforcement}

August F. Holtyn

On a multiple-schedule of reinforcement, when a rich component is followed by a relatively lean component, responding is interrupted by extended pausing. The present experiment examined whether the discriminative stimulus correlated with this rich to lean transition acquired aversive properties. Four pigeons were exposed to a compound schedule with two fixed-ratio components programmed on the center key. One component ended with the delivery of a rich reinforcer (7-s access to grain) and the second with a lean reinforcer (1-s access). Each component was correlated with a distinctive key color. At the beginning of some components, a side key was activated. A single peck on this "stimulus termination key" replaced the discriminative stimulus on the center key with a white light regardless of whether the ongoing component was rich or lean. As in previous research, pausing was a joint function of the past and upcoming conditions of reinforcement and the FR requirement. At relatively large ratios, if the upcoming reinforcer was rich, pauses were short regardless of the past reinforcer. If the upcoming reinforcer was lean, pauses were longer and the length was directly influenced by the past reinforcer; the longest pauses were observed in the transitions from a rich to a lean reinforcer. At larger ratios, removal of the multiple-schedule stimuli occurred most often in the presence of a stimulus signaling a lean reinforcer and rarely in the presence of a stimulus signaling a rich reinforcer. The past reinforcer affected the frequency of escape for two pigeons (P822 and P830); they most often terminated the lean stimulus when it was preceded by a rich reinforcer. 


\section{Acknowledgements}

I would like to thank Mike Perone, Andy Lattal, and Kevin Larkin for serving as members of my thesis committee and for their valuable comments in preparing this manuscript. I consider myself fortunate to have had the opportunity to learn from each of them. I am particularly thankful to Mike for serving as my committee chair and advisor over the past two years. 


\section{Table of Contents}

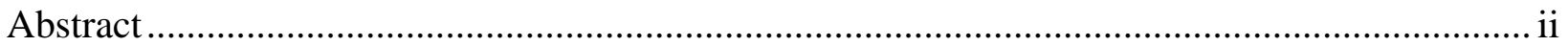

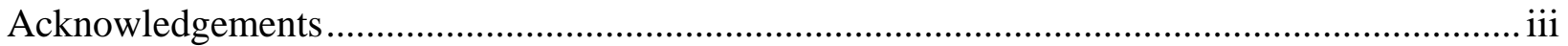

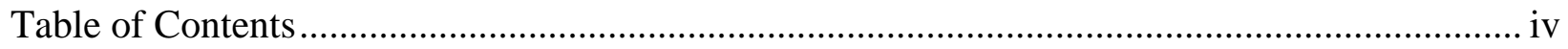

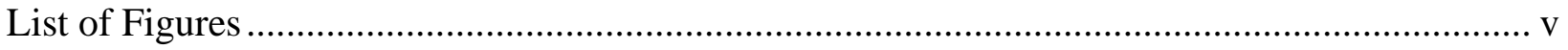

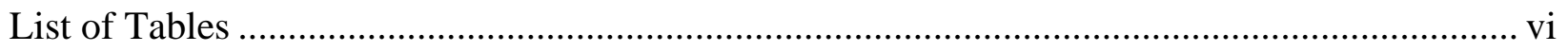

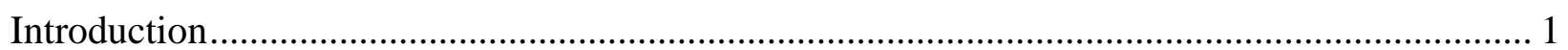

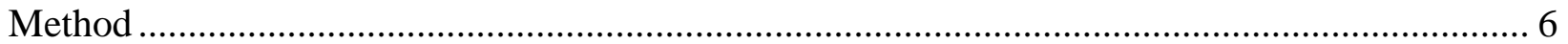

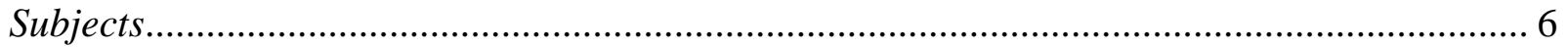

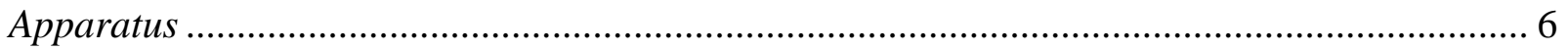

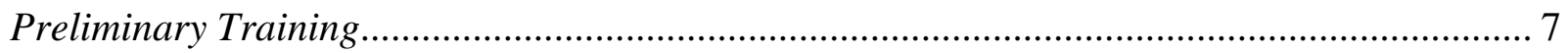

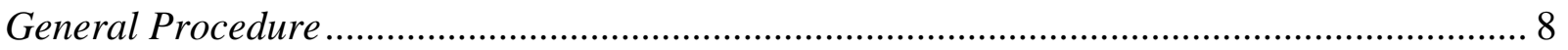

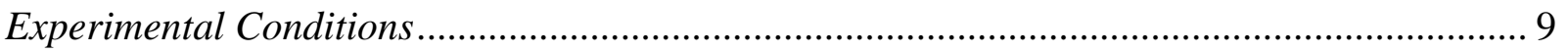

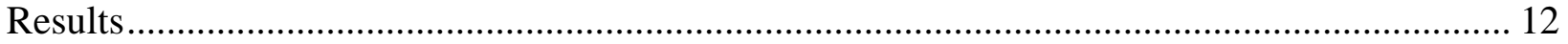

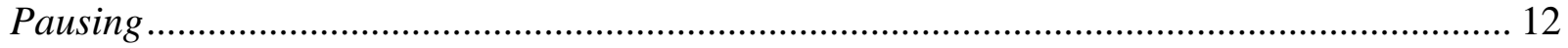

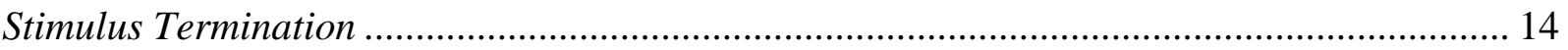

Proportion of Time in the Mixed-Schedule ..................................................................... 14

Stimulus Termination Latencies ..................................................................................... 15

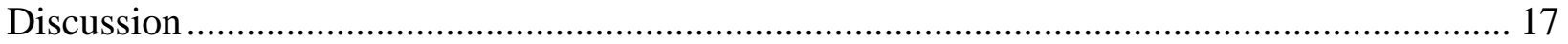

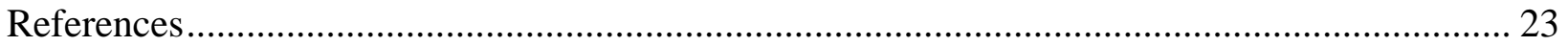




\section{List of Figures}

Figure 1. Pausing, stimulus termination (ST) responses, and the proportion of sessions spent in the mixed-schedule (MIX) as a function of the past and upcoming lean (L) and rich (R) reinforcers for each pigeon (P6888 to P822). The conditions differed in terms of FR size, shown in the top panel for each pigeon's graph. Data points represent medians and error bars represent interquartile ranges. Arrows with a number beside them indicate $75^{\text {th }}$ percentiles that exceed the

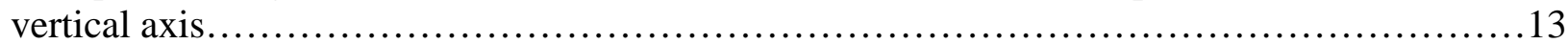

Figure 2. Latency (in seconds) to peck the stimulus termination key as a function of the past and upcoming lean (L) and rich (R) reinforcers for each pigeon (P6888 to P822). Data points represent medians and error bars represent interquartile ranges. Arrows with a number beside them indicate $75^{\text {th }}$ percentiles that exceed the vertical axis..................................16 
List of Tables

Table 1. Fixed-ratio (FR) size and number of sessions in each condition for each pigeon (P6888 to P830)...................................................................... 


\section{Introduction}

In operant research, a stimulus is aversive if its contingent removal or postponement maintains responding. Evidence for the aversive functions of shock, for example, comes from the observation that a rat will press a lever in the presence of shock when the consequence is the removal of the shock (escape). Additionally, rats will press a lever to cancel or postpone the presentation of the shock (avoidance). Numerous studies have used shock to study escape and avoidance (for reviews, see Baron, 1991; Hineline, 1977; Hutchinson, 1977). Organisms also will escape from schedules of positive reinforcement. For example, when a pigeon’s key pecking is reinforced on a fixed-ratio (FR) schedule in which access to grain is delivered after a specified number of responses, the pigeon will learn to peck another key that turns off the schedule (Appel, 1963). Such escape from schedules of reinforcement is affected by a variety of schedule parameters, such as FR size, fixed-interval (FI) length, and reinforcer magnitude (Appel, 1963; Brown \& Flory, 1972; Harzem, Lowe, \& Davey, 1975). These findings suggest that procedures typically conceptualized as reinforcement have aversive aspects (Perone, 2003).

An early demonstration of the aversive functions of positive reinforcement procedures comes from a classic study by Azrin (1961). Pigeon's pecks on one key (the food key) were reinforced on an FR schedule, and pecks on a second key (the escape key) produced a self-imposed timeout. A peck on the escape key changed the color and illumination of the houselight and the two response keys, and deactivated the food key. A second peck on the escape key reinstated the color and illumination of the houselight and the two response keys, and reactivated the food key. Thus, subjects were given the opportunity to terminate or restore stimuli correlated with the FR schedule and the FR schedule itself. Escape occurred following the delivery of a reinforcer and prior to making the run of responses required by the FR schedule. 
In other words, the pigeons escaped at the same point in the session when they were observed to pause. Azrin concluded that some schedules of positive reinforcement have aversive properties despite the absence of conventional aversive stimuli such as shock.

It is important to note that animals can escape from schedules of reinforcement when an escape option is not explicitly arranged by the experimenter. When animals pause for extended periods of time following the delivery of a reinforcer, they tend to move or turn away from the stimuli associated with the schedule (Cohen \& Campagnoni, 1989). These extended pauses are frequently generated by FR schedules (Felton \& Lyon, 1966; Powell, 1968).

A demonstration of the factors controlling pausing on FR schedules comes from Perone and Courtney (1992). Pigeons responded on compound schedules in which two types of FR schedule components alternated in a quasi-random fashion. In one component, the FR schedule produced 2-s access to grain (lean component). In the other component, the FR schedule produced 6-s access to grain (rich component). Pausing was examined in terms of four types of transitions between the schedule components: lean-lean, lean-rich, rich-lean and rich-rich.

Perone and Courtney also manipulated the presence of stimuli signaling the magnitude of the reinforcer. In one condition, a multiple schedule was programmed. In a multiple schedule, two or more schedules are presented sequentially and each schedule is signaled by a distinct stimulus. In the other condition, a mixed schedule was programmed. In a mixed schedule, two or more schedules are presented sequentially and each schedule is signaled by the same stimulus. For example, in Perone and Courtney's study, during the mixed-schedule condition the response key was lit white in both the lean and rich components. Thus, the experimental design allowed for the analysis of FR pausing as a function of past and upcoming reinforcers of different magnitudes. 
First consider Perone and Courtney’s (1992) results from the multiple schedule. In the presence of a stimulus signaling a rich reinforcer, the effects of the past reinforcer were small, with both lean and rich reinforcers resulting in brief pauses. By comparison, in the presence of a stimulus signaling a lean reinforcer, the effects of the past reinforcer were substantial; pauses following a rich reinforcer greatly exceeded pauses after a lean reinforcer. Now consider the results from the mixed schedule. In the absence of a stimulus signaling a lean or rich reinforcer, pausing in all transitions was brief or did not occur. In general, Perone and Courtney observed extended pausing when stimuli allowed discrimination of the transition from the rich to lean schedule components. When the discriminative stimuli were absent, extended pausing was also absent.

Using a procedure similar to Perone and Courtney (1992), Metzger (1990) found that pigeons would escape from the rich to lean transitions under multiple but not mixed schedule conditions. In each session, there were 40 transitions across lean (2-s access to grain) and rich (6-s access to grain) FR schedule components. An escape key was available during half of these transitions. When operative, the escape key was the same color as the food key. If the pigeon's first peck was on the escape key, the food key was darkened and deactivated, the houselight was turned off, and the escape key was dimmed. Thus, a peck on the escape key produced a selfimposed timeout. After at least 1-s had passed, a second peck on the escape key terminated the timeout, reinstated the FR schedule, relit the food key and houselight, and deactivated the escape key.

Under Metzger’s (1990) multiple-schedule conditions, pausing and escape were affected by the upcoming and past reinforcer. In the presence of a stimulus signaling a lean component, there was substantial pausing when the lean component was preceded by a rich component. 
Escape occurred more often in those transitions from a rich to lean component and the percentage of the session spent in the self-imposed timeout was greatest during these transitions. Under mixed-schedule conditions, the extended pausing within the rich to lean transitions was not observed and escape generally did not occur. Thus, the probability of escape was highest under the same conditions that produced the longest pauses. This parallels the results of Perone and Courtney (1992) who also found extended pausing in the rich to lean transitions when discriminative stimuli were present, but not in their absence. These results are consistent with Cohen and Campagnoni's (1989) suggestion that pausing in operant research functions as a form of escape from the contingencies.

The fact that pigeons escape when the lean component is signaled suggests that the lean stimulus is aversive, at least when it follows a rich component. To assess the aversive functions of the discriminative stimulus correlated with the lean component, Long (2005) used an observing procedure. As in Perone and Courtney’s study, four types of transitions between schedule components were used. Pigeons’ pecks on a center key were reinforced on a mixed schedule in which completion of an FR-100 resulted in the presentation of either 3-s access to grain (lean component) or 6-s access to grain (rich component). The center key was lit white unless the pigeons pecked the left or right key (observing keys) and changed the key color to one correlated with the current component. In some conditions, pecks on one observing key produced only the "rich stimulus," while pecks on the other could produce the "lean stimulus" or the rich stimulus. In other conditions, pecks on one observing key produced only the lean stimulus, while pecks on the other could produce the lean stimulus or the rich stimulus.

Consistent with Perone and Courtney (1992), Long (2005) found extended pausing in the rich to lean transitions, even when the discriminative stimuli were produced intermittently via an 
observing response. By measuring the probability of pecking the two observing keys, Long found that the stimulus correlated with the rich component functioned as a conditioned reinforcer: it maintained responding on the observing key that produced it. The stimulus correlated with the lean component did not function as a conditioned reinforcer: it did not maintain responding on the observing key that produced it. There was no evidence that the stimulus correlated with the lean component had aversive functions; it did not decrease responding on the observing key that produced it.

Long's (2005) failure to detect aversive properties of the stimulus correlated with the lean component appears to be at odds with Metzger's (1990) finding that such a stimulus engenders escape when preceded by a rich component. The apparent contradiction might be resolved by noting that Metzger's pigeons did more than merely escape from the lean stimulus; they also escaped from the FR schedule itself. By pecking the escape key, the pigeons not only turned off the discriminative stimuli correlated with the FR schedule, but also deactivated the center key and thus removed the opportunity to respond on the schedule. It is possible that it is the transition type that is aversive, not the stimuli correlated with it - that is, the stimuli serve only to identify the transition and allow for discrimination to occur, but do not directly cause the pause and escape behavior. Metzger's (1990) study is unable to shed light on the functions of the lean stimulus.

\section{Statement of the Problem}

In Metzger’s (1990) procedure, escape responses removed both the multiple-schedule stimuli and the opportunity to respond on the food key. Therefore, the removal of the schedule and the removal of the discriminative stimuli were confounded. The present experiment was designed to address this confound. It used a procedure similar to that of Metzger, except the 
escape key was replaced with an “off” key (stimulus termination key). A peck on the stimulus termination key converted the multiple schedule to a mixed schedule by replacing the multipleschedule stimulus with a mixed-schedule stimulus. Therefore, the only consequence of a peck on the termination key was the removal of the discriminative stimulus, while the schedule and the opportunity to respond remained in effect. If the stimulus correlated with the lean component has aversive functions when preceded by a rich component, stimulus termination behavior during the rich to lean transitions should be maintained. Responding on the termination key during all other transitions should occur less often.

Under multiple-schedule conditions, pausing and escape on compound FR schedules are affected by the past and upcoming conditions of reinforcement; however, this interaction is a function of FR size. Regardless of transition type, small ratios produce very short pauses and infrequent escape behavior. As the response requirement of the FR schedule is increased, the

probability of pausing and escape also increases (Perone, 2003). The present experiment also examined pausing and stimulus termination using different FR requirements.

Method

\section{Subjects}

Four White Carneau pigeons, each experienced with FR schedules, were maintained at $80 \%( \pm 2 \%)$ of their free-feeding body weights by grain deliveries during the experimental sessions and, if necessary, by supplemental feedings at least 30 min afterwards. Water and health grit were freely available in the home cage, which was kept in a temperature-controlled room with a 12:12 hr light/dark cycle.

\section{Apparatus}

Four sound-attenuating chambers were used. Each chamber measures $37 \mathrm{~cm}$ high, $30 \mathrm{~cm}$ wide, and $32 \mathrm{~cm}$ deep. General illumination is provided by a 28-v houselight (No.1819) located 
behind a translucent screen in the lower left corner of the front panel. Three response keys, about $2 \mathrm{~cm}$ in diameter, are arranged in a row on the front panel $24 \mathrm{~cm}$ from the floor and $9 \mathrm{~cm}$ apart, center to center. When operative, keys were illuminated from behind by $28-\mathrm{v}$ bulbs (No.1829) covered with colored caps. Food reinforcers consisted of access to mixed grain through an illuminated (No. 1819 bulb) 5-cm x 6-cm rectangular aperture located approximately $11 \mathrm{~cm}$ below the center key. When a reinforcer was delivered, the houselight and response keys were darkened and the food aperture lit. The duration of reinforcement was varied to produce rich and lean schedule components. Noise from a ventilation fan on the side of the chamber was used to mask extraneous sounds. Experimental events were controlled and recorded using microcomputers connected to the chambers by a commercial interface.

\section{Preliminary Training}

A compound schedule was used with two FR-100 components that alternated in a quasirandom fashion. The two components differed in terms of the duration of the reinforcer for completing the FR: either 1-s access to grain (lean component) or 7-s access to grain (rich component). In half of the sessions, the response key was lit with different key colors correlated with the lean and rich components, that is, a multiple schedule was programmed. The color correlated with the lean component was green (Pigeons 2317 and 6888) or blue (Pigeons 822 and 830). The color correlated with the rich component was green (Pigeons 822 and 830) or blue (Pigeons 2317 and 6888). In the other half of the sessions, the response key was lit white in both components, that is, a mixed schedule was programmed. The multiple-schedule and mixedschedule sessions were strictly alternated. At the start of each session, the schedule was randomly assigned to either the center key or the left key. Thereafter, the schedule was switched 
to the other key after every 5 components. This was done to strengthen responding on both keys. Preliminary training ended after 20 sessions were completed.

\section{General Procedure}

Sessions were conducted 7 days per week at approximately the same time of day. Prior to the start of each experimental session, the pigeons were exposed to a 5 min blackout in which the chamber lights were darkened and the keys were inactive. This was done to minimize the effects of handling on subsequent responding during the session. Sessions ended after 41 reinforcers were delivered or after 2 hrs had elapsed.

During experimental conditions, a multiple schedule was in effect on the center key (food key), with lean and rich components alternating quasi-randomly. In half of the components, the left key (stimulus termination key) was lit the same color as the food key. If the pigeon's first peck of the component was on the left key, the color of the food key was changed to white - that is, a peck on the termination key converted the schedule on the food key from multiple to mixed - and the termination key was darkened and deactivated. The mixed schedule on the food key remained in effect until the pigeon completed the FR requirement. Alternatively, if the pigeon's first peck of the component was on the food key, the termination key was darkened and deactivated and the multiple schedule remained in effect on the food key for the remainder of the component.

Forty sequences of lean and rich components, with and without the termination key available, were generated according to the following specifications. Eight types of transitions from component to component occurred within each sequence, with each transition categorized according to past and upcoming reinforcer durations as well as the presence or absence of the termination key option. Four of the transitions were based on reinforcer duration: (a) after lean, 
before lean; (b) after lean, before rich; (c) after rich, before lean and (d) after rich, before rich. Each of these transitions occurred with and without the termination key operative, yielding the eight types of transitions. Each of the eight transition types occurred 5 times per session, for a total of 40 transitions. To arrange 40 transitions, each session contained 41 components. The transitions were randomly intermixed with the following restrictions: (a) the termination key was never operative during the first or last component, (b) no more than 3 components with the termination key option occurred in succession, (c) no more than 5 lean or rich reinforcer durations occurred in succession and (d) 5 of each type of transition occurred in each session.

The 40 sequences were arranged from two sets, with 20 in each. In one set the sequences began and ended with a lean component and in the other, they began and ended with a rich component. For each pair of sessions, the sequences for the first session were randomly selected from either set and the sequence for the second session was from the other set. The selection of a sequence within a set was random with the restriction that the same sequence was not used for more than two consecutive sessions.

\section{Experimental Conditions}

Pigeons were exposed to four or five experimental conditions, which differed in terms of the size of the FR requirement in the components of the compound schedule on the food key. The size of the FR requirements ranged from 20 to 200. Table 1 shows the order of experimental conditions and the number of sessions for each subject.

Each condition lasted for at least 20 sessions and was continued until the median pause duration and the median number of stimulus termination responses was stable across the four transition types based on the past and upcoming conditions of reinforcement. Beginning with the $16^{\text {th }}$ session of each condition, the median pause and the median number of stimulus termination 
responses was calculated over a "moving window” of the most recent 10 sessions. The first median was based on the results obtained in sessions 7 through 16; the second median was based on sessions 8 through 17; and so on. When a block of five consecutive medians showed no increasing or decreasing trend, the measure was judged as stable. When the pause durations and the stimulus termination responses met the stability criterion in all four transition types simultaneously, the condition was ended. 
Table 1.

Fixed-ratio (FR) size and number of sessions in each condition for each pigeon (P6888 to P830).

\begin{tabular}{|c|c|c|c|c|c|c|c|c|}
\hline & \multicolumn{2}{|c|}{ P6888 } & \multicolumn{2}{|c|}{ P2317 } & \multicolumn{2}{|c|}{ P822 } & \multicolumn{2}{|c|}{ P830 } \\
\hline $\begin{array}{l}\text { Cond- } \\
\text { ition }\end{array}$ & FR & $\begin{array}{l}\text { Sess- } \\
\text { ions }\end{array}$ & FR & $\begin{array}{l}\text { Sess- } \\
\text { ions }\end{array}$ & FR & $\begin{array}{l}\text { Sess- } \\
\text { ions }\end{array}$ & FR & $\begin{array}{l}\text { Sess- } \\
\text { ions }\end{array}$ \\
\hline 1 & 80 & 20 & 100 & 20 & 100 & 20 & 100 & 28 \\
\hline 2 & 40 & 30 & 160 & 24 & 200 & 41 & 200 & 25 \\
\hline 3 & 20 & 20 & 50 & 20 & 50 & 20 & 50 & 20 \\
\hline 4 & 80 & 21 & 160 & 45 & 200 & 32 & 25 & 21 \\
\hline 5 & --- & --- & --- & --- & --- & --- & 200 & 27 \\
\hline
\end{tabular}




\section{Results}

The results are expressed in terms of pausing, stimulus termination, and the proportion of the session spent in the mixed-schedule (i.e., the proportion of the session spent in escape from the multiple-schedule stimuli) as a function of the past and upcoming conditions of reinforcement. Analyses are based on data from the last 10 (stable) sessions of each condition. Pausing was measured in the components without the stimulus termination option, from the start of the component until the first peck on the food key. Thus, pausing was measured in 200 transitions over the stable sessions of each condition (4 types of transition x 5 instances of each type $\mathrm{x} 10$ sessions). The data on stimulus termination (the number of responses emitted on the termination key) and time spent in the mixed schedule are from the transitions in which the termination key was available; there were also 200 of these transitions over the stable sessions of each condition.

Figure 1 shows pausing, stimulus termination responses, and the proportion of the session spent in the mixed-schedule for each pigeon. The magnitude of the past reinforcer is displayed on the $\mathrm{x}$-axis and the magnitude of the upcoming reinforcer is represented by filled and unfilled circles. The FR size in each condition is shown in the top panel of each pigeon's graph. The circles represent medians and the vertical lines extend from the $25^{\text {th }}$ to the $75^{\text {th }}$ percentiles.

\section{Pausing}

The top panel of each graph shows pausing as a function of the past and upcoming conditions of reinforcement. Pauses were short and undifferentiated across all transitions when the ratio requirement on the food key was relatively small. In comparison, when the ratio requirement was relatively large, pausing varied as a function of the transition. During the transitions in which there was an upcoming rich reinforcer (filled circles), the effects of the past 

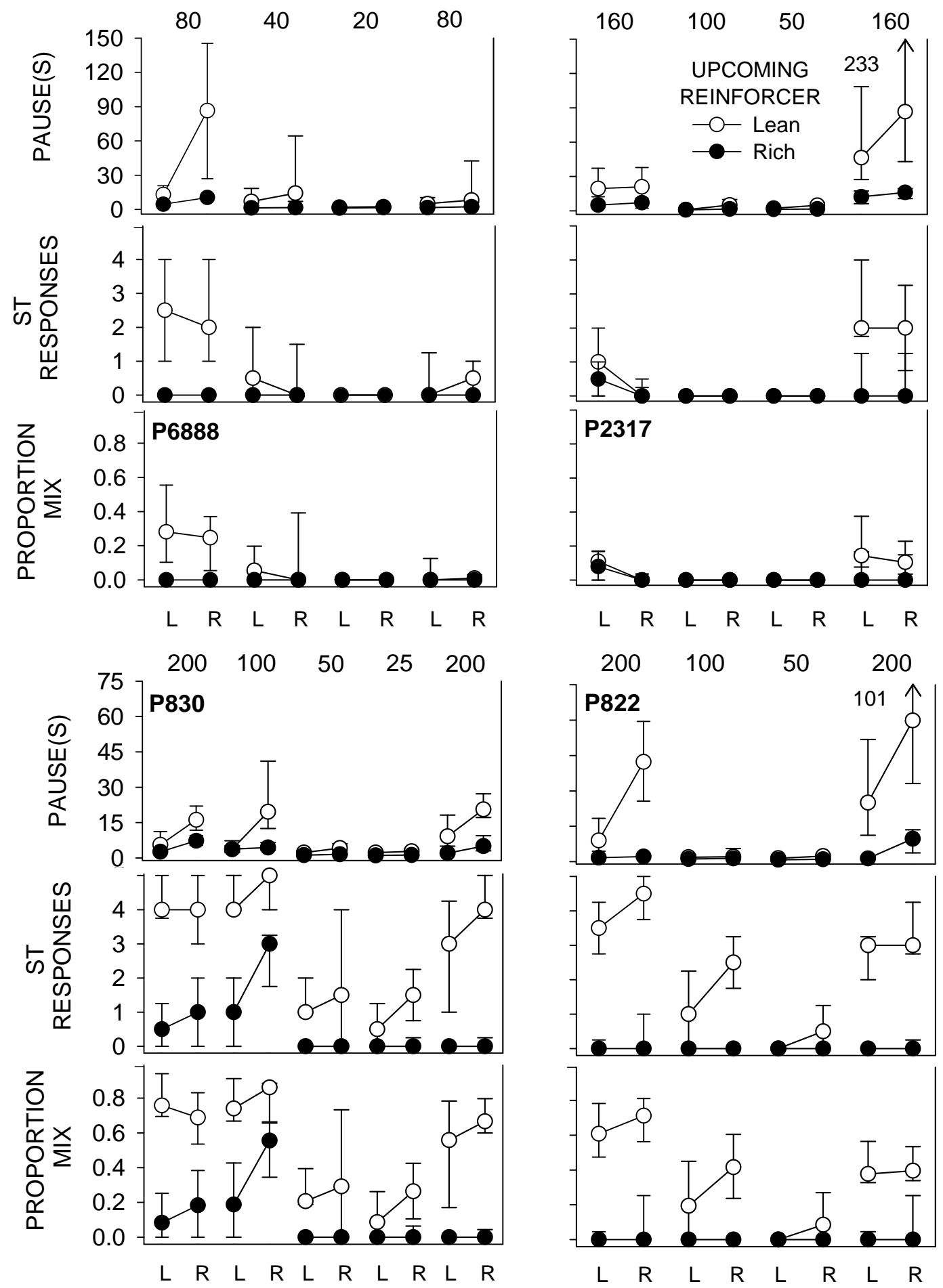

PAST REINFORCER

Figure 1. Pausing, stimulus termination (ST) responses, and the proportion of sessions spent in the mixed-schedule (MIX) as a function of the past and upcoming lean (L) and rich (R) reinforcers for each pigeon (P6888 to P822). The conditions differed in terms of FR size, shown in the top panel for each pigeon's graph. Data points represent medians and error bars represent interquartile ranges. Arrows with a number beside them indicate $75^{\text {th }}$ percentiles that exceed the vertical axis. 
reinforcer were fairly small, resulting in brief pauses regardless of whether the past reinforcer was lean or rich. During the transitions in which there was an upcoming lean reinforcer (unfilled circles), pausing was extended when the past reinforcer was rich. Thus, pausing was a joint function of the past and upcoming conditions of reinforcement and the FR size.

\section{Stimulus Termination}

Stimulus termination responses for each pigeon are shown in the middle panels of Figure 1. When the ratio requirement was relatively large, termination of the multiple-schedule stimulus was more likely to occur. At relatively small ratio requirements, stimulus termination either did not occur or occurred to a lesser extent. In the presence of a stimulus signaling an upcoming lean reinforcer, stimulus termination was more likely. In addition, two pigeons (P830 and P822) showed evidence of joint control by the past and upcoming conditions of reinforcement: In most transitions from a rich to a lean reinforcer, the number of termination responses was highest, relative to the other transitions. The exceptions were in the initial FR 200 condition for P830 and the second FR 200 condition for P822.

\section{Proportion of Time in the Mixed-Schedule}

The bottom panels of Figure 1 show the outcome of pecking the stimulus-termination key: the proportion of the session spent in the mixed-schedule. The mixed-schedule stimulus was rarely in effect when the FR requirement was relatively small, whereas when the requirement was relatively large, the mixed-schedule stimulus was more prevalent. Turning on the mixed-schedule stimulus occurred most often when it replaced the multiple-schedule stimulus signaling an upcoming lean reinforcer. In addition, some evidence of joint control can be seen in P830 and P822. 


\section{Stimulus Termination Latencies}

Figure 2 shows the latency to peck the stimulus termination key as a function of the past and upcoming conditions of reinforcement for each pigeon. Latencies to peck the stimulus termination key were short across all transitions when the ratio requirement on the food key was relatively small. In comparison, when the ratio requirement was relatively large, the latency to peck the stimulus termination key was extended. Latencies were longer in the presence of a stimulus signaling a lean reinforcer. Thus, at higher ratios, the pigeons waited for longer periods of time before escaping from the lean stimulus. Evidence of joint control can be seen in 7 of the 8 conditions in which the largest FR requirements were in effect. The exception was the initial FR 160 condition for P2317. 

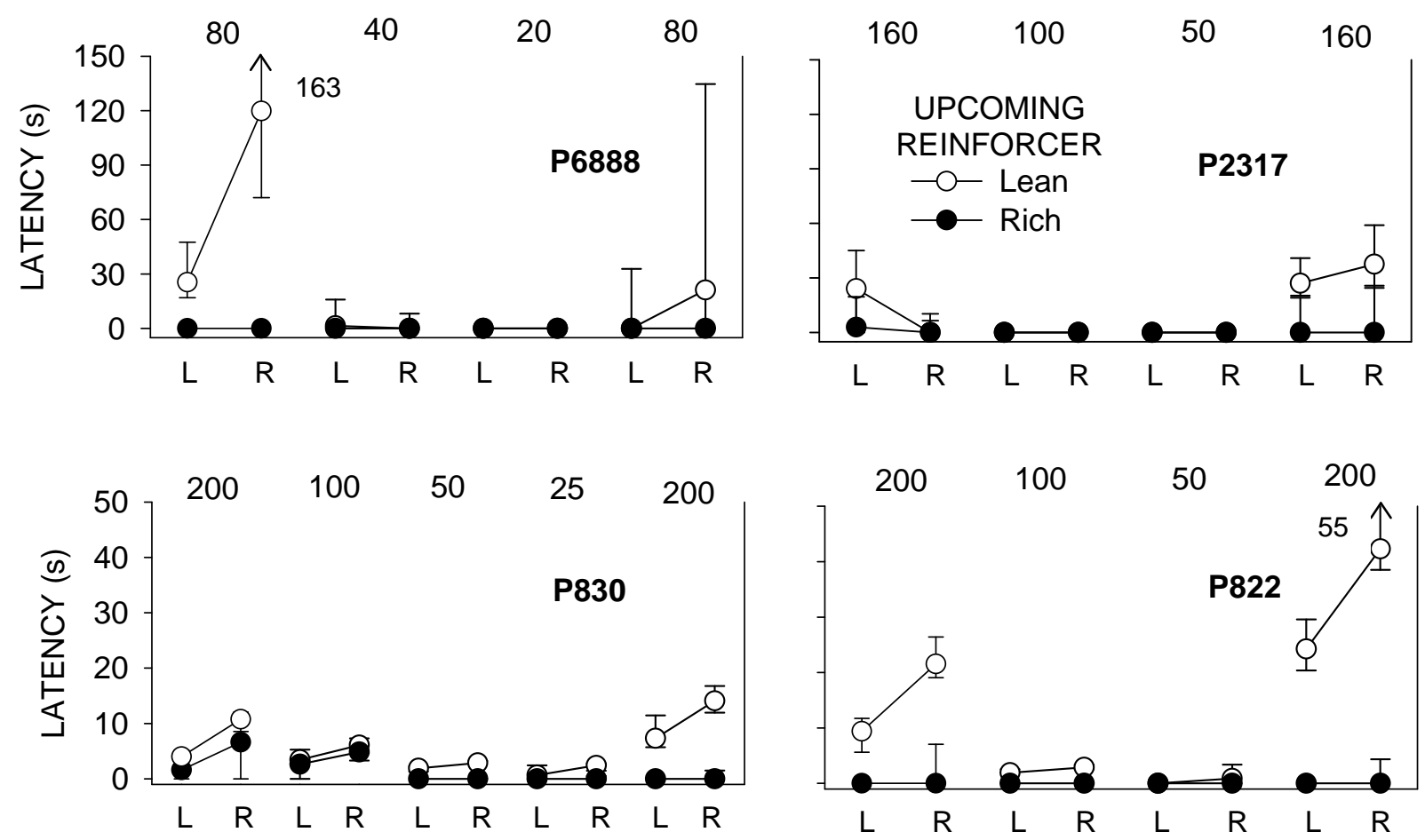

\section{PAST REINFORCER}

Figure 2. Latency (in seconds) to peck the stimulus termination key as a function of the past and upcoming lean $(\mathrm{L})$ and rich $(\mathrm{R})$ reinforcers for each pigeon (P6888 to P822). Data points represent medians and error bars represent interquartile ranges. Arrows with a number beside them indicate $75^{\text {th }}$ percentiles that exceed the vertical axis. 


\section{Discussion}

The present experiment examined whether stimuli correlated with transitions between lean and rich components acquired aversive functions. Pigeons were exposed to compound schedules with two FR components. These components, each signaled by a distinctive key color, ended in the delivery of either a lean or rich reinforcer. At the beginning of some components, a side key was activated that, if pecked, could replace the discriminative stimulus correlated with the current component with a white light. That is, a peck on this key converted a multiple schedule to a mixed schedule. This arrangement was designed to assess some factors that might control pausing and escape on FR schedules.

Pausing was a joint function of the past and upcoming conditions of reinforcement and the FR size. At relatively large ratios, if the upcoming reinforcer was rich, pauses were short regardless of the past reinforcer. If the upcoming reinforcer was lean, pauses were longer and the length was directly influenced by the past reinforcer. The longest pauses were observed in the transitions from a rich to a lean reinforcer at larger ratios (see Figure 1). This finding is consistent with previous research demonstrating the interaction of these variables in controlling pausing on FR schedules (Perone, 2003; Perone \& Courtney, 1992).

The present study provides further evidence that a stimulus correlated with the leaner of two schedules can develop aversive functions. Escape from the lean stimulus was predominantly controlled by the upcoming conditions of reinforcement and the FR size. At larger ratios, removal of the multiple-schedule stimuli occurred most often in the presence of a stimulus signaling a lean reinforcer and rarely in the presence of a stimulus signaling a rich reinforcer. The past reinforcer affected the frequency of escape for two pigeons (P822 and P830); they most often terminated the lean stimulus when it was preceded by a rich reinforcer. 
Previous research supports the present finding that a lean stimulus can develop aversive properties. Jwaideh and Mulvaney (1976) reinforced responding on a center key using a mixed VI-30 s VI-120 s schedule. Two observing keys were available that, if pecked, could convert the mixed schedule to a multiple schedule. If the VI-30 s component was in effect, all three keys were lit green, whereas if the VI-120 s component was in effect, all three keys were lit red. In the conditions of interest, a peck on one observing key produced only green (the rich stimulus), while a peck on the other observing key could produce either the rich stimulus or red (the lean stimulus), depending on the component that was in effect. The rate of observing was lower on the key that produced both the lean and rich stimuli. Jwaideh and Mulvaney concluded that the lean stimulus functioned as a conditioned punisher because it suppressed responding on the observing key that produced it.

If a stimulus correlated with the leaner of two schedules can function as a conditioned punisher, it follows that it should also engender escape. Dinsmoor, Thiels, Lee, Pfister, and Dougan (1989) demonstrated that pigeons would reliably turn off, or escape from, a stimulus correlated with the leaner of two schedules. In their experiment, pigeons pecked a center key on a compound schedule in which a VI 60-s schedule of food reinforcement alternated with an extinction (EXT) component. Independent of responding, the color of the center key would switch between a multiple-schedule condition in which key colors were correlated with the VI and EXT components, and a mixed-schedule conditions in which the center key was yellow regardless of the schedule component. Two side keys were made available that could turn the discriminative stimuli on and off. The pigeons pecked the "on” key in the presence of the mixed stimulus and the "off” key in the presence of the stimulus correlated with the EXT component. 
Thus, the stimulus correlated with EXT was aversive because its removal maintained responding on the off key.

An interesting feature of the present results can be seen in the latency to peck the termination key at larger ratios. In the presence of the lean stimulus, the pigeons waited for longer periods of time before removing the multiple-schedule stimulus correlated with the lean component. These longer latencies to terminate the lean stimulus might be interpreted as evidence that the stimulus was not especially aversive; if the lean stimulus was aversive, one would assume that the pigeons would terminate this stimulus more quickly. However, latencies may have been extended under these conditions because of the manner in which the termination option was presented. To remove the multiple-schedule stimulus, and escape to the mixedschedule stimulus, the pigeons had to come into contact with the stimulus currently in effect. That is, the pigeons were required to orient towards and peck a key that was lit with the lean stimulus. Because of this requirement, longer latencies would be expected if the lean stimulus was indeed aversive.

This interpretation, although speculative, is amenable to experimental analysis. The present study could be replicated while changing the location of the termination option. The termination key could be placed on the wall opposite from the response panel and lit with the mixed-schedule stimulus. A peck on this key would again darken and deactivate the key and convert the multiple-schedule in effect on the center key to a mixed-schedule. This arrangement would not require the pigeons to contact the lean stimulus to escape to the mixed-schedule stimulus. Therefore, moving or turning away from the response panel would not directly compete with removal of the stimulus by a peck on the termination key. Changes in the latency to peck the termination key could then be examined. 
Moving or turning away from the response key - behavior that is measured as pausing all reduce contact with the stimuli correlated with the current conditions and can function as a form of escape. Two pigeons (P2317 and P6888) infrequently pecked the stimulus termination key. They may have failed to do so because they were moving or turning away. Experimenter observations during the sessions support this notion. Because these pigeons frequently turned away from the lean stimulus, removal of the lean stimulus via a peck on the termination key was reinforced less often than removal of the stimulus by turning away (see Figure 1). These pigeons did contact the consequences of pecking the termination key within experimental sessions and, at larger ratios, there was an increase in responding on the termination key immediately after raising the FR requirement, but this behavior decreased after a few sessions. This transitory effect, which was not captured by the steady state data, is consistent with the results of Zimmerman and Ferster (1964). They reported that increasing the FR requirement caused an immediate increase in responding on an escape key, but that responding on this key did not last for more than a few sessions. In the present experiment, a longer reinforcement history of escape by turning away from aversive stimuli may have impeded maintenance of responding on the termination key for pigeons P2317 and P6888.

The present results may be compared to the contradictory results of Metzger (1990) and Long (2005). Metzger demonstrated that pigeons would impose a timeout in the presence of a stimulus signaling an upcoming lean component and concluded that the lean stimulus was aversive, at least when it was preceded by a rich component. These results were incompatible with Long, who found that the lean stimulus did not function as a conditioned punisher. It was suggested that it might be the transition type and not the stimuli that develop aversive functions; the stimuli would serve only to discriminate the transitions without directly influencing escape. 
The present experiment does not support this interpretation; the stimuli do not merely serve a discriminative function, but develop aversive properties. Why the lean stimulus did not function as a conditioned punisher in Long's study remains unclear, especially in light of the results of Dinsmoor, Thiels, Lee, Pfister, and Dougan (1989) and Jwaideh and Mulvaney (1976).

The question that should then be asked is why Long's (2005) study failed to detect any aversive properties of the lean stimulus. Recall that although Long's study did not show that the lean stimulus can function as a conditioned punisher, there was no evidence that it functioned as a conditioned reinforcer; it appears that the lean stimulus was neutral in its effects. Given that the parameters used in the present study (in terms of the FR requirement and reinforcer magnitude) are similar to those used by Long, it is unlikely that the differences seen can be attributed to the parameters used. Worth noting is that in Long's study, in the critical comparisons, responding on one observing key produced the rich stimulus or the lean stimulus, whereas responding on another key produced only the rich stimulus. It was concluded that the lean stimulus did not function as a conditioned punisher because responding was equally high on both of these observing keys. Perhaps control by the rich stimulus overrode the effects of the lean stimulus. That is, observing may have been predominantly controlled by the reinforcing properties of the rich reinforcer. The observing responses in Long's study may have been less sensitive to control by conditioned aversive stimuli than the termination responses in the present experiment.

The responding of pigeons P2317 and P6888 varied substantially with that of P822 and P830. These two pigeons (P2317 and P6888) pecked the termination key infrequently and responding on this key was not controlled by the interaction of the past and upcoming conditions of reinforcement. The variability of responding may be a function of the limited number of 
reinforcer magnitudes and FR requirements that were assessed in the present experiment. Future research examining a variety of parametric manipulations seems warranted to determine if joint control by the past and upcoming conditions of reinforcement may be generated through manipulation of the FR requirements and reinforcer magnitudes. 


\section{References}

Appel, J. B. (1963). Aversive aspects of a schedule of positive reinforcement. Journal of the Experimental Analysis of Behavior, 6, 423-428.

Azrin, N. H. (1961). Time-out from positive reinforcement. Science, 133, 382-383.

Baron, A. (1991). Avoidance and punishment. In I.H. Iversen \& K.A. Lattal (Eds.), Experimental analysis of behavior, Part I. (pp. 173-217). Amsterdam: Elsevier.

Brown, T. G., \& Flory, R. K. (1972). Schedule-induced escape from fixed-interval reinforcement. Journal of the Experimental Analysis of Behavior, 17, 395-403.

Cohen, P. S., \& Campagnoni, F. R. (1989). The nature and determinants of spatial retreat in the pigeon between periodic grain presentations. Animal Learning and Behavior, 17, 39-48.

Dinsmoor, J. A., Thiels, E., Lees, D. M., Pfister, J., \& Dougan, J. D. (1989). Selective observing: Pigeons turn discriminative stimuli on and off by pecking separate keys. In N.W. Bond \& D.A.T. Siddle (Eds.), Proceedings, XXIVth International Congress of Psychology: Vol. 6 Psychobiology: Issues and applications (pp. 443-456). Amsterdam: Elsevier.

Felton, M., \& Lyon, D. O. (1966). The post-reinforcement pause. Journal of the Experimental Analysis of Behavior, 9, 131-134.

Harzem, P., Lowe, C. F., \& Davey. G. C. L. (1975). After-effects of reinforcement magnitude: Dependence upon context. Quarterly Journal of Experimental Psychology, 27, 579-584.

Hineline, P. N. (1977). Negative reinforcement and avoidance. In W. K. Honig \& J. E. R. Staddon (Eds.), Handbook of Operant Behavior. (pp. 364-414). Englewood Cliffs, New Jersey: Prentice-Hall, Inc. 
Hutchinson, R. R. (1977). By-products of aversive control. In W. K. Honig \& J. E. R. Staddon (Eds.), Handbook of Operant Behavior. (pp. 415-432). Englewood Cliffs, New Jersey: Prentice-Hall, Inc.

Jwaideh, A. R., \& Mulvaney, D. E. (1976). Punishment of observing by a stimulus associated with the lower of two reinforcement frequencies. Learning and Motivation, 7, 211-222.

Long, J. B. (2005). The behavioral functions of stimuli signaling transitions across rich and lean schedules of reinforcement. Unpublished master's thesis, West Virginia University.

Metzger, B. (1990). Escape from fixed-ratio schedules as a function of reinforcer magnitude. Unpublished master’s thesis, West Virginia University.

Perone, M. (2003) Negative effects of positive reinforcement. The Behavior Analyst, 26, 1-14.

Perone, M., \& Courtney, K. (1992). Fixed-ratio pausing: Joint effects of past reinforcer magnitude and stimuli correlated with upcoming magnitude. Journal of the Experimental Analysis of Behavior, 57, 33-46.

Powell, R. W. (1968). The effect of small sequential changes in fixed-ratio size upon the post-reinforcement pause. Journal of the Experimental Analysis of Behavior, 11, $589-593$.

Zimmerman, J., \& Ferster, C. B. (1964). Some notes on time out from reinforcement. Journal of the Experimental Analysis of Behavior, 7, 13-19. 